\title{
Pathological and Molecular Diagnosis of Paratuberculosis in Sheep and Goats
}

\author{
P. Kanimozhi, M. Geetha*, K.M. Palanivel and M. Arthanari Eswaran
}

Department of Veterinary Preventive Medicine, Veterinary College and Research Institute, Namakkal, Tamil Nadu Veterinary and Animal Sciences University, Tamil Nadu, India

*Corresponding author

\section{A B S T R A C T}

\begin{tabular}{|c|}
\hline Keywords \\
\hline $\begin{array}{l}\text { Johne's disease, } \\
\text { Mycobacterium } \\
\text { Avium Subsp. } \\
\text { Paratuberculosis, } \\
\text { PCR, Sheep and } \\
\text { goats }\end{array}$ \\
\hline Article Info \\
\hline $\begin{array}{l}\text { Accepted: } \\
12 \text { July } 2018 \\
\text { Available Online: } \\
10 \text { August } 2018\end{array}$ \\
\hline
\end{tabular}

\section{Keywords}

Johne's disease, Mycobacterium Avium Subsp. Paratuberculosis, goats

Article Info

Johne's disease is a chronic granulomatous bacterial disease of livestock caused by Mycobacterium avium Subsp. Paratuberculosis (MAP) characterized by progressive weight loss, chronic enteritis and poor response to treatment (Moges et al., 2016). It mainly affects dairy cattle, sheep and goats and has also been reported in horses, pigs, deer, rabbits (Greig et al., 1999). The first reported case of JD in sheep was diagnosed in 1967 - 1968 in Zaanen breed of goats (Zoi Dimareli- Malli, 2010). It has
Johne's disease (JD) is caused by Mycobacterium avium Subsp. Paratuberculosis (MAP) and the disease is characterized by chronic diarrhea, progressive weight loss and emaciation. The present study was carried out to find out the MAP infection status by postmortem and molecular diagnosis in sheep and goats suspected for JD. Postmortem examination of six small ruminants (One sheep and five goats) revealed the pathognomonic necrotic findings such as characterised hypertrophy of mucosal surfaces of small intestine (terminal ileum) and cord like thickening of mesenteric lymphnodes. Acid
Available Online:

Introduction fast staining of cytological smears prepared from the intestinal scrapings and mesenteric sequence of MAP which revealed positivity to MAP infection. The study concluded that postmortem examination combined with polymerase chain reaction is highly useful in accurate diagnosis of JD in small ruminants. lymphnode and intestine were collected from during postmortem examination and subjected to polymerase chain reaction (PCR) using specific primers targeting IS 900 gene 
immune-sorbent assay (ELISA), Agar gel immunodiffusion (AGID) and complement fixation test (CFT) (Munir et al., 2014). The insertion element IS 900 PCR has been routinely used to detect the presence of MAP as it was shown to be specific for MAP (Collins et al., 1989). The present study describes the pathological and molecular diagnosis of JD in small ruminants.

\section{Materials and Methods}

Mesenteric lymph node and intestine from one sheep and five goat carcasses were collected during post mortem examination at Veterinary College and Research Institute (VC\&RI), Namakkal, Tamil Nadu and postmortem lesions noticed were observed and recorded. The samples were collected by aseptic manner in a sterile container and stored at $-20^{\circ} \mathrm{C}$ until further processing. Cytology smears were prepared from intestinal scrapings and mesenteric lymphnode and stained by acid fast staining technique as per the protocol recommended by Singh et al., (2014). By using Qiagen stool mini DNA kit (Qiagen, USA) DNA was extracted from mesenteric lymph node and intestine as per the protocol described by Mobius et al., (2007). Polymerase chain reaction was performed as per the method described by Millar et al., (1995) using the primer set of forward: 5'GAA GGG TGT TCG GGG CCG TCG CTT AGG -3' and reverse: 5'-GGC GTT GAG GTC GAT CGC CCA CGT GAC-3' targeting IS 900 gene

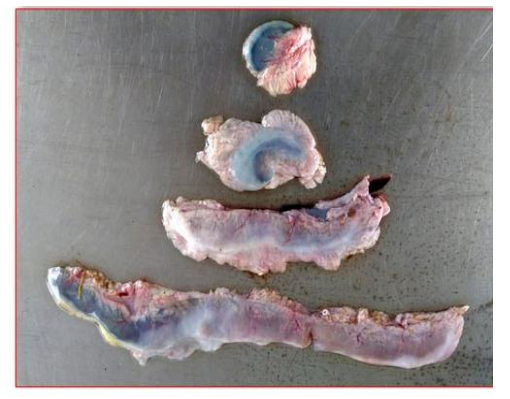

Fig.1 Cord like thickening mesenteric lymphnodes in Johne's disease sequence of MAP. The amplified PCR products were electrophoresed in $1.8 \%$ agarose gel and positivity to MAP infection was detected by visualization of amplified PCR product size of $413 \mathrm{bp}$.

\section{Results and Discussion}

Postmortem examination of six small ruminants (One sheep and five goats) which showed the significant gross lesions like enlargement of mesenteric lymph nodes (Fig. 1) and hypertrophy of intestinal mucosal folds exhibiting typical "corrugation" (Fig. 2). The observed findings of the study are in correspondence with the reports of Sharif et al., (2013) who reported that the enlargement of mesenteric lymphnodes and thickening of small intestinal mucosal folds with typical corrugations is pathognomic to JD. Hence based on necropsy findings the disease was diagnosed as JD.

Acid fast staining of cytological smears made from the intestinal scrapings and mesenteric lymph nodes of the animals showed the presence of acid fast bacilli. Visualization of groups of brightly pink coloured bacilli in acid fast stained smears or sections of tissues (intestines near ileo- cecal valve or mesenteric lymph nodes) is highly suggestive of paratuberculosis (Singh et al., 2014). Based on the findings of above author the results of the present study revealed the positivity of the animals to MAP infection.

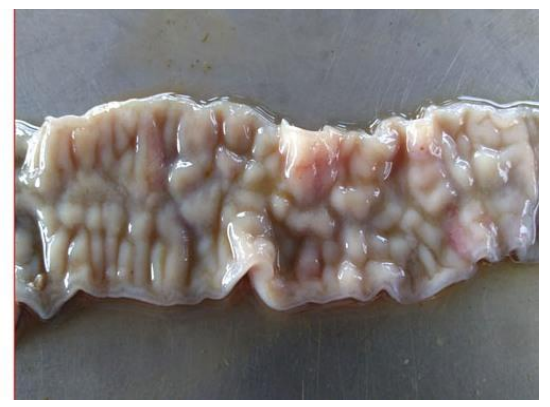

Fig.2 Corrugation of small intestinal mucosa in Johne's disease 


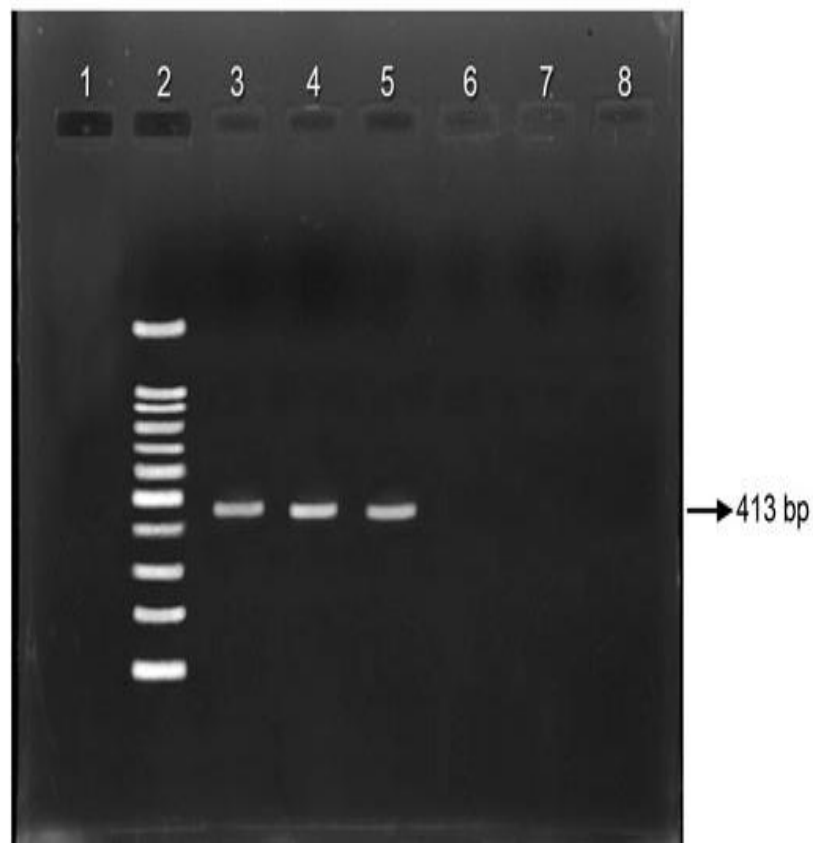

Fig.3 IS 900 gene specific PCR for Mycobacterium avium subsp. Paratuberculosis - Mesenteric lymph node and intestine

Cappuccino and Sherman (2008) reported that acid fast staining of intestinal impression smears and mesenteric lymphnode was highly useful in diagnosis of MAP infection. Sikandar et al., (2013) reported that superiority of intestinal samples over mesenteric lymph node for the diagnosis of paratuberculosis with $\mathrm{ZN}$ staining technique. The results of the present study are in correlation with the findings of above authors.

Polymerase chain reaction confirmed the MAP infection status of the all animals. Tissue DNA extracted from intestine and mesenteric lymph node of all animals (one sheep and five goats) were subjected to IS 900 gene specific PCR for MAP which revealed positivity by showing 413 bp of PCR product (Fig. 3). Singh et al., (2007) used IS 900 PCR for detection of MAP in intestine and mesenteric lymph nodes of ovines in India. Bauerfeind et al., (1996) reported that the IS 900 provides a valuable tool in epidemiological studies of paratuberculosis in sheep and it is highly useful for the etiological diagnosis of JD in farm animals. It is concluded that necropsy and PCR can be used together for accurate diagnosis of JD in small ruminants

\section{Acknowledgements}

The authors acknowledge TANUVAS authorities for providing necessary facilities for carrying out their study.

\section{References}

Bauerfeind, R., B. W. Samira, S. Reinhard Theodor, W. Hermann and G. Baljer, 1996. Molecular characterization of Mycobacterium paratuberculosis isolates from sheep, goats and cattle by hybridization with a DNA probe to insertion element IS900. J. Clin. Microbiol., 7:1617-1621.

Buregelt, C.D., and P.E. Ginn, 2000. The histopathologic diagnosis of subclinical Johne ${ }^{e e}$ disease in North American Bison (Bison bison). Vet. Microbiol., 77(3-4): 325-331.

Cappuccino, J.G. and N. Sherman, 2008. 
Microbiology. A Laboratory Manual. $7^{\text {th }}$ Ed, Dorling Kindersley, India, pp. 7779.

Collins, D.M., D.M. Glabric and G.W. Lisle, 1989. Identification of a repetitive DNA sequence specific to Mycobacterium paratuberculosis. FEMS Microbiolo. Lett., 60: 175-178.

Greig, A., K. Stevenson, D. Henderson, V. Perez, V. Hugues, I. Pavlik, M.E. Hines, I. Mckendrick and J.M. Sharp, 1999. Epidemiological study of paratuberculosis in wild rabbits in Scotland. J. Clin. Microbiol., 37: 17461751

Millar, D., J. Ford, J. Sanderson, S. Withey, M. Tizard, T. Doran and J. Hermon Taylor, 1995. IS 900 PCR to detect Mycobacterium paratuberculosis in retail supplies of whole pasteurized cow milk in England and Wales. Appl. Environ. Microbiol., 62: 3446- 3452.

Mobius, P., H. Helmut, R. Astrid and K. Hrike, 2007. Comparison of 13 single round and nested PCR assays targeting IS 900, IS Mav2, f 57 and iocus 255 for detection of Mycobacterium avium subspecies paratuberculosis. Vet. Microbiol., 126: 324-333.

Moges, S., S. Mohammed, G. Gashaw, H. Belete, Z. Mebrae and K. Hayat 2016. Review on bovine paratuberculosis. World. J. of Pharma. Med. Res, 2: 1724.

Munir, M., J.M. Garrido, G. Aduriz and M.V. Geijo, 2014. Detection of Mycobacterium avium subspecies paratuberculosis in ovine faeces by direct quantitative PCR has similar or greater sensitivity compared to radiometric culture. Vet. Microbiol, 125: 36-48.

Sharif. K., S. Sarman, and K. Gopinath, 2013. Mycobacterium avium subspecies paratuberculosis and Crohn's Regional Illeitis. Jou. Lab. Phy., 3: 69-74.

Sikandar, A., A.H.Cheema, M. Adil, M. Younus, H. Zaneb, M.A. Zaman, M. Tipu and S. Masood, 2013. Ovine paratuberculosis - A histopathological study from Pakistan. J. Anim. and plant. sci., 23: 749-753.

Singh, S.V., A.V. Singh, J.S. Sohal and A.V. Singh, 2007. Evaluation of an indigenous ELISA for diagnosis of Johne's disease and its comparison with commercial kit. Indian, J. Microbiol., 47: 251-258.

Singh, S.V., A.V. Singh, A. Kumar, P.K. Singh, R. Deb, A.K Verma, A. Kumar, R. Tiwari, S. Chakraborthy and K. Dharmaf, 2013. Survival mechanisms of Mycobacterium avium subspecies paratuberculosis within the host species and in the environment. A Review. Nat.Sci., 5: 710- 723.

Singh, P.K., S.V. Singh, H.Kumar, J.S. Sohal and A.V. Singh, 2014. Diagnostic application of IS 900 PCR using blood a a source sample for the detection of Mycobacterium avium subspecies paratuberculosis in early and subclinical cases of caprine paratuberculosis. Vet. Med. Int., doi: 10.4061/2010/748621.

Zoi Dimareli - Malli, M, 2010. Detection of Mycobacterium avium subspecies paratuberculosis in Milk from clinically affected sheep and goats. Intern J. Appl. Res. Vet. Med., 8: 921-945.

\section{How to cite this article:}

Kanimozhi, P., M. Geetha, K.M. Palanivel and Arthanari Eswaran, M. 2018. Pathological and Molecular Diagnosis of Paratuberculosis in Sheep and Goats. Int.J.Curr.Microbiol.App.Sci. 7(08): 2360-2363. doi: https://doi.org/10.20546/ijcmas.2018.708.237 